\title{
Topology optimization and rim design
}

\author{
A. RASHWAN \\ University of Debrecen, Faculty of Engineering, Department of mechanical engineering,
}

Abstract: A goal of this article is to show the development of the car wheel rims along with the progress of the manufacturing technologies over the past few years. To achieve this goal, topology optimization and generative design usage have been reviewed in this work. The research has focused on the main factors, which affect the life of car wheel rim, and it has shed the light on the effect of the topology optimization and the generative design on the manufacturing of the car wheel rims. Since the main factors above-mentioned are the: forces, material preferences and topology optimization, the study has covered the results of the studies made on each part along with the technology progress. Moreover, the article has explained the methodology main steps of the topology optimization and the generative design and their principles.

\section{Introduction}

Nowadays, almost every industry seeks to manufacture the parts required by the market using less and less material but still the main characteristics of the parts is to be kept intact or even better. And the best option to get this result was the topology optimization process. TO topology optimization is defined by most of the researchers as: the process of getting the best design or form after a careful analysis of the design under the real life conditions (constraints, loads ....etc.).

"Topology optimization is a methodology to derive an optimal material distribution for a design under given usage conditions," said Jeffrey Brennan. By a simpler definition, topology optimization continues to trim the part under study until it gets the best shape and design of it. One of the good examples on that matter is how to reach the strongest possible design and still using the least amount of material.

Along with the topology optimization, the term Generative design has become more popular also, and it refers to a more generic term that uses the computational process to help assist in the design process. Consequently, the topology optimization can be defined also as a set of generative designs, which gather to give the best results expected.

However, the generative design or the topology optimization processes often produce extremely complex and strange results for the designs in terms of manufacturability, which brings us to the fact that using the traditional manufacturing processes is no more an option after using such analysis methods.

The most recent development of the generative design is the additive manufacturing process, a generation of manufacturing machinery, which allows the designers to build even the strangest most complex designs. Thus it enables manufacturers to use the highest forms of analysis software to get 
the best designs without having to worry about the manufacturability possibilities available to use after finishing the design stage.

\section{Use of TO and GD (Generative Design) in car wheel rim design:}

The rim of the wheel in the car sustains many forces during the functioning of the car, since the wheels are in direct contact with the road; they exert many forces on the rims. Companies in the field have been trying to eliminate the failures occurring to the rims along their service and most importantly, they have been trying to manufacture more durable rims with lighter weight all through using the topology optimization and the generative design process before manufacturing the product in order to get the best design.

Here in the rim manufacturing, the good shape of the rim also matters to most of the car companies, a part where all the car-manufacturing companies take as a competence.

The topology optimization has offered the industry a great deal of help in this field, where the duty of the designer is to give the software the initial design of the wheel rim and the result will be a topologically optimized part where a good shape, durable design, and a part which can be manufactured with one of the additive manufacturing methods.

\section{Engineering optimization:}

The techniques used in the optimization have reached a great level in recent years according to the increasing demand of production, and the application of the optimization have covered a wide variety of industries: chemical, construction, automotive, aerospace, construction, electrical and manufacturing industries. It is understood that the advanced level of computer technology has had the greatest effect on the optimization especially that the optimization programs have to offer solution to the complex problems of the initial designs proposed by designers.

The general definition of the optimization can be summarized as the process of generating the optimum results being studied under the real circumstances given in a certain system. It is a balance between the factors, which affect the industry of a certain product, i.e. offering the designer the option to choose which function to optimize and showing its effect from many aspects. For example, optimization can offer the designer whether to increase the benefit of minimizing the stress in a product while in the same time the help to reduce the material used in the production.

Optimization algorithms and system differ in acting with the solutions to be offered, all of which are of mathematical background using many equations that can deal with the design to get the user some good results at the end of the day.

Researchers have originated the idea of the optimization back to the World War II. During the war, many problems have encountered the British army with how to allocate the resources that were scarce and limited in amount on several activates. There was no systematic approach for solving this issue, mathematicians were called to develop some scientific methods to find some solutions for such problem, and they achieved a great success and got the British the victory in the Air Battle. 
The mathematicians have applied many optimization processes. One of them was the linear programming, which was the result of many mathematical operations to find the solution for allocation, but over time, it has become an algorithm to solve designing problems. Finally, we can say that based on the field of study, certain optimization methods arise to optimize the whole process of designing and manufacturing the products needed in that same field.

\section{Topology optimization:}

The topology optimization is a set of mathematic rules and sets of equations, which have arisen from the need of optimizing the shape of a certain design. Due to the necessity of carefully choosing the materials in a certain industry, the topology optimization have offered great solutions in order to get the most sustainable products.

To simplify the topology optimization process, the researchers have defined the steps of this process by the following:

- Creating an initial design for the required product.

- $\quad$ The FEA follows; there will be a finite element analysis.

- The optimization algorithms will take this round.

- The new design will result in the previous stages.

- A check whether the reached design is the best options for the process or not.

- If yes, then it will be the end, and if not, the next iteration will take place to try different analysis variables.

This diagram will summarize the steps of the topology optimization process: 


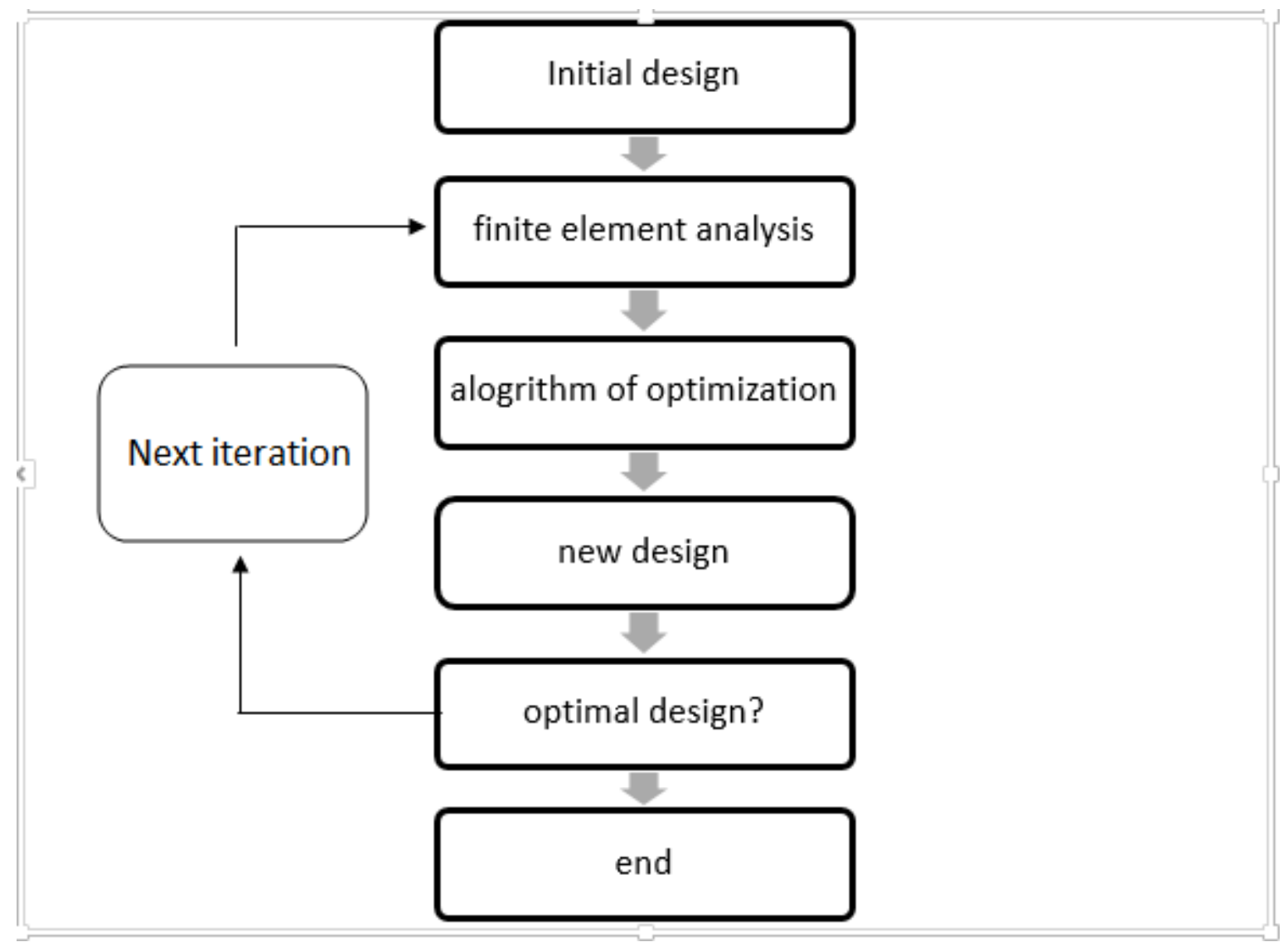

Topology optimization process steps

\section{Literature review:}

In the literature review, let us review the use of the topology optimization in the industry of wheel rims taking into consideration three main topics, which largely affects the manufacturing of the product under research:

- $\quad$ Forces: the studies concerned with the effect of the forces on the rim industry and they have been developed.

- $\quad$ Material preferences: studies which were concerned with the materials used to have a durable structure in the wheel rims.

- $\quad$ Topology optimization: the title, which will be also studied on the previous two titles, in general the whole literature review is a revision on the use of the topology optimization and how each factor was affected by that.

\section{Forces:}

Since the rim of the wheel sustains most of the dynamic and static forces and loads during the functioning of the car, many studies have taken care of analyzing them to understand the real circumstances in terms of the forces. Forces are main part of the analysis process, whether we are 
talking in general or in the topology optimization software usage. As we all know, setting the analysis session will require setting the forces under which the system is acting.

Meyer-Pruessner has started the first study in this regard [10]. Where he stated: "It is very important to select carefully the loading on components as they have a high impact on the topology optimization's results."

Trzesniowski [11] has created some equations and formulas with which we are able to calculate the loads and forces generated on the wheel's rims. Concerning the fatigue loads, they can be calculated under the conditions defined by the SAE recommendations [12].

\section{Material preferences:}

The wheel rims are inseparable parts of the car which go along with it all the way through, and the rims have to withstand the conditions that the car goes through like turning -which brings more forces- and braking under high speeds. A high force that acts on the rim along with time is called the fatigue stress, which might not be an easy factor to forget. All these conditions dictate on the manufacturers to have materials up to the challenge.

Still, in the middle of caring about the durability of the material to be used, scientists have developed a great interest in the lightweight materials such as magnesium, titanium....etc. Alongside the durability, there must be good-looking car rims, because it is one of the most attractive accessory to be cared for by the car lovers around the world.

Saran Theja \& Vamsi [14] Krishna, have suggested the use of the magnesium alloys in the rim's industry, because it has some "superior characteristics" as they have stated many times. Later, Pekguleryuz, Kainer, \& Kaya who assured the magnesium to be a good choice for the racing cars, have verified the same result.

Dong, Liu, Ding, \& Zou [15] introduced some interesting methods to get better types of alloys through the heat treatment of the alloys surface especially on the magnesium Mg ZK60-T5. However, the use of magnesium is still a matter of question since it has a bad disadvantage, which is the corrosion although most of the new treatment have succeeded to prevent the corrosion by some technological means.

M. Sabari et.al [16] conducted several studies on the materials used in the rim's manufacturing but with the help of the software available at that time. His main interest was in the aluminum alloys and the carbon steel. The result of his study can be summarized: the deformation possibility happening in the aluminum alloys in the rim is higher than that using the carbon steel one. The result might be good in terms of the durability, but still it does not meet the requirement of the car manufacturing companies in terms of the lightness and low cost of the whole story.

T. Siva Prasad et.al [17] conducted an intensive study on the pros and cons on many famous materials to be used in the rims manufacturing industries, like aluminum, Magnesium, steel, and he added the carbon fiber to be investigated as well. The study was not in favor of using the aluminum because of the high displacement as stated by the researcher and proved the steel to be a suitable material rather than the rest of the chosen materials. 
Sourav Das [18] used the optimization process to assess the quality of the material to be used in the rim. Mostly focused on the aluminum and magnesium, as he was interested in the lightweight materials. The study was useful in terms of aesthetic terms but still the results in the durability field were not satisfactory.

As a conclusion, many materials have been selected in the field, aluminum alloys magnesium alloys steel alloys and forged steel. In fact, no material has been selected to be perfect choice but still every material has its own advantages and disadvantages. The choice can be made according to the manufacturer's perspective and ambitions.

\section{Topology optimization on car wheel rims:}

The topology optimization was used in the beginning on the whole body structure of the car design, and then started getting into smaller details like the parts of the chassis and reaching the wheel rims.

Norberg \& Lövgren [19] were concerned in the topology optimization of the whole body of the car, and their objective was the same as ours concerning the wheel rim. They encouraged getting lighter chassis of a car, and still good durability.

Xiao, Zhang, Liu, He, \& Shan [20] conducted a thorough study on the rim analysis using the topology optimization software, the study considered the steel as a material of the rim and it showed a chart indicating some good results concerning the durability and the characteristics of the rims analyzed.

Many studies were focused on getting the best shape and design from the rim using the topology optimization and have developed throughout the years, from the analysis of the stress and showing the weakest points, until suggesting better options. This, of course, can be acquired from the original proposed design of the product in general, and the rim in particular, since it is our research topic.

\section{Overview on the application of topology optimization and generative design in rim design using SolidEdge:}

A simple case study on the rim topology optimization will be as follows:

- Drawing the CAD file of the initial rim design.

- $\quad$ Defining the material to be used for the rim.

- $\quad$ Setting the loads under which the rim is acting.

- $\quad$ Setting the constraints with which the rim is fixed.

- $\quad$ Applying the analysis and understanding the results

- $\quad$ Choosing the best shape and design to be manufactured

The next figures will show us how to apply these steps using SolidEdge ST 10 as a software.

The following figure 1 shows the initial CAD design drawing for the rim: 


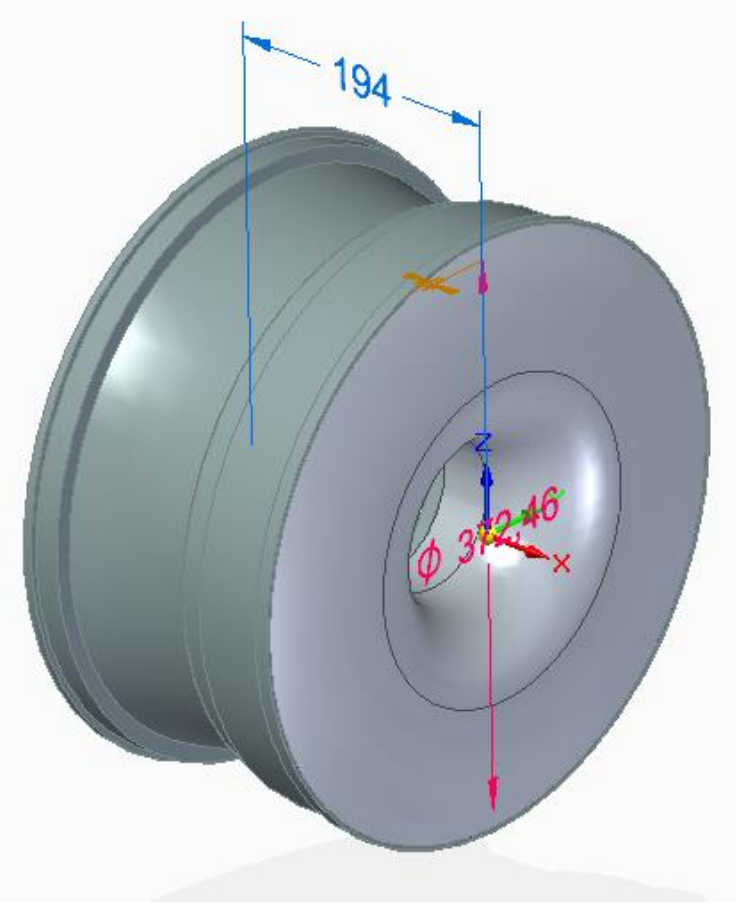

Fig1 initial CAD drawing

After careful consideration by the designer, the initial design is drawn leading us to the next step in the topology optimization which is the material selection from the software: a dropdown list allows us to choose the material from several standard materials and alloys, in our case we can use the steel as an initial selection:

The next step takes care of applying the loads represented by the forces under which the rim design is functioning. Here comes the point where we can set the constraints which rules the motion and fixture of the wheel rim, it is important to carefully pay attention to cover all the actual constraints applied to the design, because it will affect the accuracy of the results.

When all the parameters have been set and given to the program, the software is ready to apply the generative design analysis on the design, we can set the extent to which we want our topology optimization to go to, for example: the amount of material to be removed as a percentage or as real value. Next figure 2 shows the part as it is ready for the process with the meshing preview. 


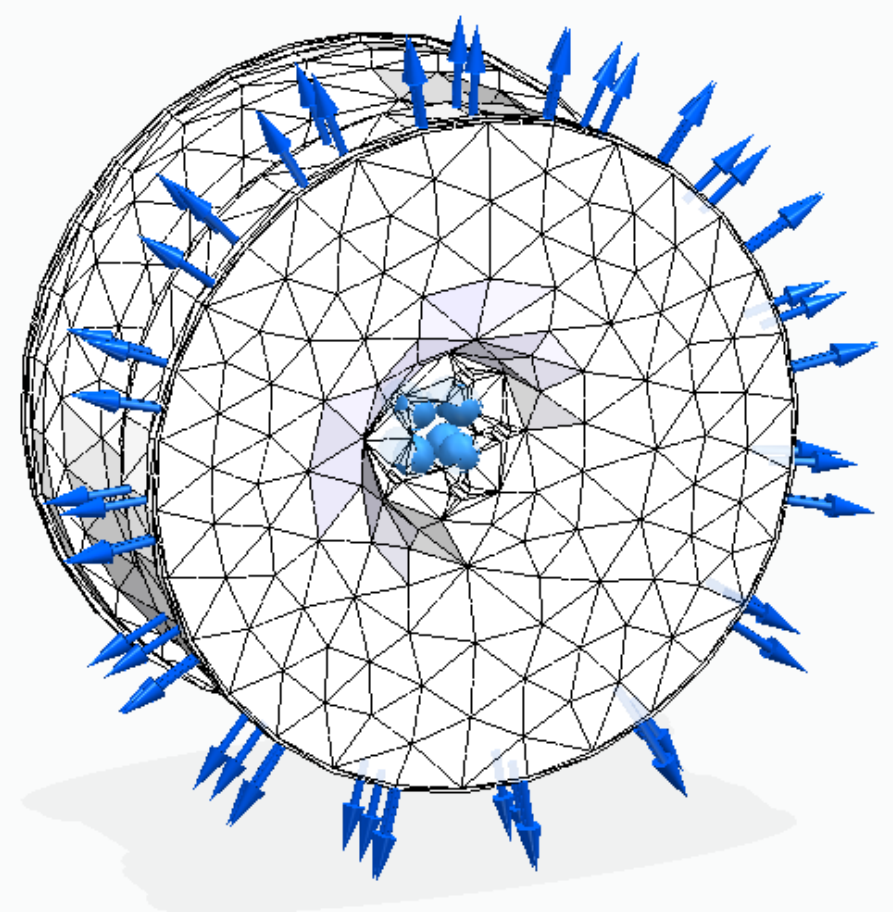

Fig2 the part ready for analysis

The final step in the analysis process is applying the study on the ready part, the solver then processes the data given and analyzes the part and shows the results for the topologically optimized part. The figure 3 shows the results of the process:

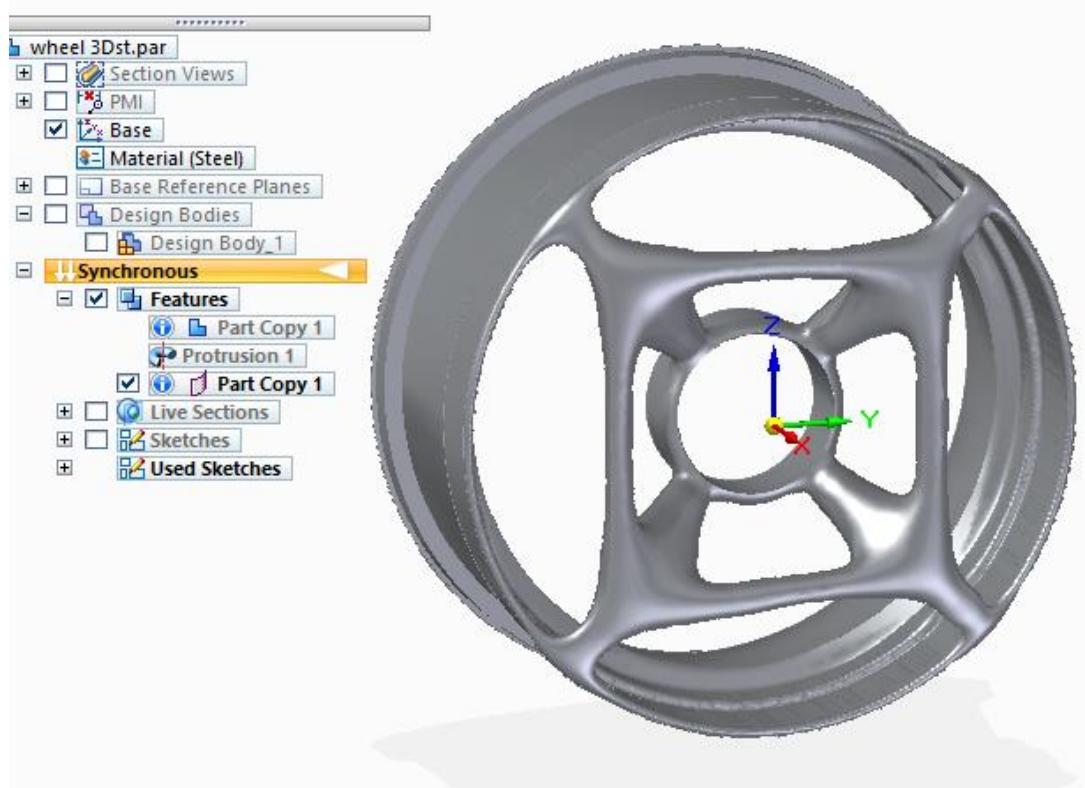

Fig 3 the analysis process results

After the whole process, the designer can decide if the result is fine to be manufactured or still there is a need to modify some conditions to get better results or simply create a different analysis situation. 


\section{Conclusions:}

Nowadays, the topology optimization along with the generative design are the best option for any designer and manufacture in the markets, and it shows us the best iteration derived from the initial design that we have put our thought in.

The best of the study still relies on the ability of the analyzer using the topology optimization, if the software is to be filled with good parameters, the results might be closer to the optimum outcome. Understanding how the topology optimization strategy works gives the designer a privilege to overcome the rest of the normal designers.

In our field, the experience in setting the whole study as close as possible to the real life conditions of the car makes a better designer and seemingly a better result.

\section{References}

[1] Jeffrey Brennan, Altair chief marketing officer and senior vice president, Global Markets.

[2] Engineering Optimization, Theory and Practice, Fourth Edition, Singiresu S. Rao, 4th ed.

[3] J. Arora, Introduction to Optimum Design, 2nd ed., Academic Press, San Diego, 2004.

[4] C. S. Wolfe, Linear Programming with BASIC and FORTRAN, Reston Publishing Co.,

[5] Reston, VA, 1985

[6] Mankovits, Tamás ; Szabó, Tamás ; Kocsis, Imre ; Páczelt, István Optimization of the Shape of AxiSymmetric Rubber Bumpers STROJNISKI VESTNIK-JOURNAL OF MECHANICAL ENGINEERING 60 : 1 pp. 61-71., 11 p. (2014)

[7] Mankovits, Tamás ; Kocsis, Imre ; Portik, Tamás ; Szabó, Tamás ; Páczelt, István Shape Design of Rubber Part Using FEM INTERNATIONAL REVIEW OF APPLIED SCIENCES AND ENGINEERING 4 : 2 pp. 85-94. , 10 p. (2013)

[8] Mankovits, Tamás ; Szabó, Tamás Finite Element Analysis of Rubber Bumper Used in Air-springs PROCEDIA ENGINEERING 48 pp. 388-395. , 8 p. (2012)

[9] Kocsis, Imre ; Mankovits, Tamás Application of Non-parametric Regression in Engineering Optimization ANALELE UNIVERSITATII DIN ORADEA FASCIOLA MANAGEMENT SI INGINERIE TEHNOLOGICA / ANNALS OF THE UNIVERSITY OF ORADEA FASCICLE OF MANAGEMENT AND TECHNOLOGICAL ENGINEERING 12 : 22 pp. 159-162. , 4 p. (2013)

[10] M.Tech Student, QIS College of Engineering \& Technology, Ongole - 523272, Andhra Pradesh 2 Professors, Department Of Mechanical Engineering,

[11] Significant Weight Reduction by Using Topology Optimization in Volkswagen Design Development with emphasis on engine design Part 2.

[12] Rennwagentechnik: Grundlagen, Konstruktion, Komponenten, Systeme, Vieweg+Teubner. Vieweg+Teubner.

[13] Standard, Wheels - Passenger Car and Light Truck Performance Re-quirements and Test Procedures. SAE. SAE.

[14] PG Student, Mechanical Engineering Department, JCEI's Jaihind College of Engineering, Pune, Maharashtra, India. 
[15] Structural and Fatigue Analysis of Two Wheeler Lighter Weight Alloy Wheel. IOSR Journal of Mechanical and Civil Engineering, 8(2), 35-45.

[16] Surface Characteristics and High Cycle Fatigue Performance of Shot Peened Magnesium Alloy ZK60.

[17] M. Sabri, M. Rezal, A. Mu'az, K. Shahril, J. Ihsan, “Deformation Behaviour analysis of Car Wheel Rim under Different Loading Using Finite Element Method", international Journal of Engineering and Technology, pp- 181-184, Volume 5, No.3, March, 2015

[18] Siva Prasad, T. Krishnaiah, J. Md. Iliyas, M. Jayapal Reddy "A Review on Modeling and Analysis of Car Wheel Rim using CATIA \& ANSYS" at International Journal of Innovative Science and Modern Engineering (IJISME) ISSN: 2319-6386, Volume-2, Issue-6, May 2014.

[19] Design and Weight Optimization of Aluminum Alloy Wheel" by Sourav Das, (CAE Analyst) Altair Engineering India Pvt Ltd, Bangalore at International Journal of Scientific and Research Publications, Volume 4, Issue 6, June 2014 ISSN 2250-3153

[20] Norberg, E., \& Lövgren, S. (2012).

[21] Xiao, D., Zhang, H., Liu, X., He, T., \& Shan, Y. (2014). Novel steel wheel design based on multiobjective topology optimization. ournal of Mechanical Science and Technology, 28(3), 1007-1016.

[22] K.J. Bathe, "Finite Element Procedures in Engineering Analysis”, Prentice-Hall, Inc.

[23] Pekguleryuz, M. O., Kainer, K. U., \& Kaya, A. A. (2013). Fundamentals of Magnesium Alloy Metallurgy. Oxford: Woodhead Publishing.

[24] Singiresu S. Rao, Topology optimization origins

[25] Abaqus 6.12 Online Documentation. Version 6.12. Dassault Syst emes, 2012.

[26] Michaël BRUYNEEL, Jean-Charles CRAVEUR, Pierre GOURMELEN (2014). Optimisation des Structures Mécaniques : Methodes numériques et éléments finis. Paris : DUNOD, $334 \mathrm{p}$.

[27] Faculty of Science, Technology and Communication University of Luxembourg, Campus Kirchberg, 6 rue Coudenhove-Kalergi L-1359 Luxembourg, Luxembourg. 